\title{
Use of n-alkanes for estimation of voluntary intake and digestibility in donkeys (Equus asinus)*
}

\author{
O.A. Castelán-Ortega ${ }^{1,4}$, J.G. Estrada-Flores ${ }^{1}$, D.G. Smith ${ }^{2}$, \\ B. Colunga ${ }^{1}$, A. Solís-Méndez ${ }^{1}$, F. Avilés-Nova ${ }^{3}$, A. Ramirez ${ }^{1}$ \\ and I. García ${ }^{1}$
}
${ }^{1}$ Centre for Research in Agriculture Sciences of the Autonomous University of the State Mexico, Literary Institute, No. 100, CP. 50000, Toluca, México
${ }^{2}$ Department of Agriculture and Forestry, University of Aberdeen
Abredeen AB24 4FA, United Kingdom
${ }^{3}$ Temascaltepec University Centre of the Autonomous University of the State Mexico CP. 5130, Temascaltepec, México

\begin{abstract}
The aim of this work was to evaluate if the n-alkanes (C32) technique can be used to determine voluntary dry matter intake (DMI) and dry matter digestibility (DMD) in grazing donkeys. Two experiments were carried out; in trial $1 \mathrm{DMI}$ and DMD were measured using n-alkanes in four caged donkeys. In trial 2, n-alkanes were used to predict DMI and DMD in six donkeys grazing a star grass sward (Cynodon nlemfluensis). Results from both experiments suggest that the $\mathrm{n}$-alkanes technique can be used to predict DMI and DMD with similar results than those obtained with other more sophisticated or expensive techniques.
\end{abstract}

KEY WORDS: donkey, n-alkanes, voluntary intake, digestibility

\section{INTRODUCTION}

The donkeys in Mexico's rural areas are usually fed crop residues, weeds, roadside verges and natural pastures. However, little is known about voluntary dry matter intake of grazing donkeys. In the past the accurate estimates of dry matter intake (DMI) of grazing animals have been problematic because of the lack of reliable techniques. The alkanes pair technique (APT) was recently, developed and validated

\footnotetext{
* Supported by The Donkey Sanctuary and the Universidad Autónoma del Estado de Mexico, Grants $1470 / 2000$ S and $1783 / 03 \mathrm{U}$

${ }^{4}$ Corresponding author: e-mail: oaco@uaemex.mx
} 
in a variety of ruminant species to estimate DMI in grazing animals (Mayes et al., 1988). To a limited extent this method has also been validated in horses by Ordakowski et al. (2001) and most recently in donkeys fed temperate grasses by Smith et al. (2007). The APT uses a naturally occurring odd-chain alkane (usually $\mathrm{C} 31$ or C33) and a dosed adjacent even chain alkane (usually C32) to estimate DMI (Mayes and Dove, 2000). There is little available information about the voluntary DMI in grazing donkeys and since DMI is the main constrain to nutrient consumption and digestibility of diets, the aim of this work was to use and validate the n-alkanes (C32) technique to determine DMI and DMD in caged animals and then test the technique in donkeys grazing star grass.

\section{MATERIAL AND METHODS}

Two 22 days trials were carried out; in each experiment the first 15 days were for diet adaptation, and the last seven for sample collection. The even chain alkane was hand dosed to each donkey individually three times per day from day 1 to 21 in both trials.

\section{Trial 1 (T1)}

The alkanes pair technique (APT) was calibrated and validated under controlled conditions in this experiment before its application in grazing animals (trial 2). Four donkeys with an average liveweight (LW) of $113.4 \pm 8 \mathrm{~kg}$ were placed in $2.5 \mathrm{~m}^{2}$ individual cages. LW was recorded daily during the sample collection week in order to keep the donkeys on a constant weight because they were also used to estimate digestible energy requirements (Carretero et al., 2005). A mixed diet composed of $85 \%$ chopped maize straw ( $5 \mathrm{~cm}$ particle size) and $15 \%$ lucerne hay was offered twice daily (08.00 and $16.00 \mathrm{~h}$ ). The total daily amount of feed offered was calculated as $2 \%$ LW on a DM basis. Refusals were collected and weighted in order to calculate in vivo apparent intake.

Trial 2 (T2)

Six donkeys with an average LW $121.3 \pm 11.5 \mathrm{~kg}$ were kept on a star grass (Cynodon nlemfluensis) sward for the duration of the experiment. No other forage or supplement was provided. In both experiments water was freely available.

\section{External marker preparation}

Five grams of n-alkane $\mathrm{C} 32$ was diluted in 4.01 of n-heptane at $60^{\circ} \mathrm{C}$ and kept under agitation and constant heat. Then $4 \mathrm{ml}$ of this solution were added to 
a $10 \mathrm{~g}$ biscuits which served of medium for administration. After the heptane had evaporated each biscuit contained $50 \mathrm{mg}$ of alkanes. A biscuit was offered three times per day so $150 \mathrm{mg}$ n-alkanes were dosed per donkey.

\section{Sample collection}

In $\mathrm{T} 1150 \mathrm{~g}$ of forage samples were taken daily during the collection week, dried at $60^{\circ} \mathrm{C}$ to constant weight and kept for analyses. Faecal samples per donkey were collected for the last 5 days. Gravimetric measurement of the total daily faecal output (DFO) of each donkey was carried out for the final 5 days of the experiment. The DFO of each donkeys was thoroughly mixed at the end of each collection day and a small sample $(100 \mathrm{~g})$ taken and frozen until the end of the experiment. Once the study had finished, all faecal samples were defrosted and $50 \mathrm{~g}$ sub-samples of the daily faecal samples from each donkey were pooled to make a single pooled faecal sample per donkey. These pooled samples were then dried at $60^{\circ} \mathrm{C}$ and retained for laboratory analysis. For T2 grass samples collection was carried out in the last seven days using a $0.25 \times 0.25 \mathrm{~m}^{2}$. Quadrants were thrown at random three times daily before and after grazing. The herbage was then cut within the quadrant using scissors approximately $1 \mathrm{~cm}$ from the ground (as it would be grazed by the donkeys). The herbage was then dried at $60^{\circ} \mathrm{C}$. In the last five days $100 \mathrm{~g}$ of faeces were taken directly from rectum of each animal and the process above described for $\mathrm{T} 1$ for faeces processing was repeated.

\section{Alkane analysis}

Alkane concentrations were determined according to Ali et al. (2004) technique. All analyses were carried out in duplicates in $25 \mathrm{~m} \times 0.32 \mathrm{~mm}$ capillary column, type BP1 (SGE) which was fitted in a Pye Unicam 4400 gas chromatograph. Faecal recovery of each odd chain alkanes was calculated as in Equation 1 (Ordakowski et al., 2001):

$$
R=\frac{O \times C o}{I \times C i} \times 100
$$

where: $R$ - faecal recovery (\%); $O$ - mean faecal output (kg DM /d); Co - oddchain alkane concentration in faeces, $\mathrm{mg} / \mathrm{kg} \mathrm{DM} ; I$ - intake, (kg DM/d); $C i$ - alkane concentration in the diet, $\mathrm{mg} / \mathrm{kg} \mathrm{DM}$.

The DMI was calculated as in Equation 2 and DM digestibility (DMD) as in Equation 3 (Gudmundsson and Gudrun, 1998):

$$
D M I=\frac{F i / F j \times D j}{H i-F i / F j \times H j}
$$


where: $D M I$ - dry matter intake (kg DM/d), Dj - daily alkane dose (mg/d), Fi faecal dry matter concentration of odd-chain alkane $(\mathrm{mg} / \mathrm{kg} \mathrm{DM}), \mathrm{Hi}$ - dry matter concentration of the odd-chain alkane in diet (mg/kg DM), Fj - faecal dry matter concentration of the even-chain alkane ( $\mathrm{mg} / \mathrm{kg} \mathrm{DM}), \mathrm{Hj}$ - concentration of evenchain alkane in diet ( $\mathrm{mg} / \mathrm{kg} \mathrm{DM})$.

$$
D M D=(1-\mathrm{Hi} / \mathrm{Fi}) \times 100
$$

Faecal output (FO) was calculated as proposed by Dove and Mayes (2003) in Equation 4:

$$
F o=\frac{M D R}{F M C}
$$

where: Fo - faecal output ( $\mathrm{kg} \mathrm{DM} / \mathrm{d}), M D R$ - external alkane dosed rate $(\mathrm{mg} / \mathrm{d})$, $F M C$ - faecal external alkane concentration ( $\mathrm{mg} / \mathrm{kg} \mathrm{DM})$.

The means of in vivo and alkane values for DMI, DMD and FO of T1 were analysed by $t$ test in order to check the accuracy of APT predictions in relation to in vivo observations.

\section{RESULTS}

Alkane concentrations in the diet and faeces are shown in Table 1. During T1 the concentration of C31 alkane within the forage was highest $(73.9 \mathrm{mg} / \mathrm{kg} \mathrm{DM})$ followed by C29 and C33. In T2, C33 had the highest concentration in forage and faeces.

Table 1. Average concentrations of alkanes in the diet and faeces of donkeys, $\mathrm{mg} / \mathrm{kg} \mathrm{DM}$

\begin{tabular}{cccccc}
\hline \multirow{2}{*}{ Trial } & \multicolumn{5}{c}{ Alkanes } \\
\cline { 2 - 6 } & C25 & C27 & C29 & C31 & C33 \\
\hline Diet & & & & \\
T1 & $6.6 \pm 0.3$ & $15.3 \pm 1.0$ & $49.8 \pm 5.4$ & $73.9 \pm 14.4$ & $23.6 \pm 1.0$ \\
T2 & $5.9 \pm 1.2$ & $14.1 \pm 2.4$ & $33.0 \pm 3.7$ & $92.9 \pm 9.9$ & $102.7 \pm 12.1$ \\
Faeces & & & & & \\
T1 & $7.0 \pm 1.4$ & $22.6 \pm 0.5$ & $77.9 \pm 6.7$ & $109.5 \pm 8.1$ & $58.4 \pm 1.6$ \\
T2 & $7.9 \pm 1.8$ & $21.7 \pm 5.4$ & $58.5 \pm 11.4$ & $160.9 \pm 24.4$ & $170.5 \pm 3$ \\
\hline
\end{tabular}

\pm - standard deviation

Faecal recovery of alkanes is shown in Figure 1. The highest recovery was found for C33 followed by C31 and C29, whereas the lowest recovery was observed for C25. There was no significant difference between DMI measured directly and that predicted using APT (Table 2) for T1. Table 3 shows DMI, DMD and FO measured during T2. 


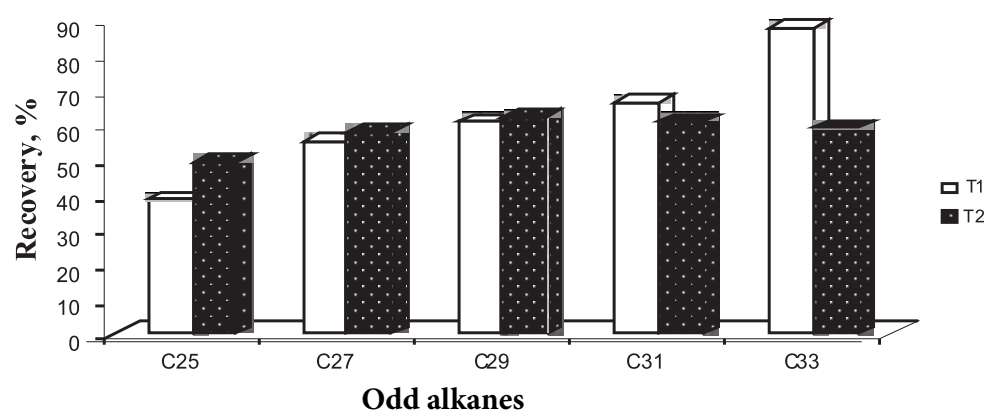

Figure 1. Average faecal recovery (\%) of alkanes for donkeys in T1 and T2

Table 2. Average DMI, DMD and FO observed in vivo vs predicted values using APT (c31:c32:c33)

\begin{tabular}{lcccccc}
\hline & $\begin{array}{c}\text { In vivo DMI } \\
\mathrm{kg} \mathrm{DM} / \mathrm{d}\end{array}$ & $\begin{array}{c}\text { APT DMI } \\
\mathrm{kg} \mathrm{DM} / \mathrm{d}\end{array}$ & $\begin{array}{c}\text { In vivo DMD } \\
\%\end{array}$ & $\begin{array}{c}\text { APT DMD } \\
\%\end{array}$ & $\begin{array}{c}\text { Observed FO } \\
\mathrm{kg} \mathrm{DM} / \mathrm{d}\end{array}$ & $\begin{array}{c}\text { APT FO } \\
\mathrm{kg} \mathrm{DM} / \mathrm{d}\end{array}$ \\
\hline Mean & $2.7^{\mathrm{a}}$ & $2.3^{\mathrm{a}}$ & $44.0^{\mathrm{a}}$ & $46.0^{\mathrm{a}}$ & $0.95^{\mathrm{a}}$ & $1.0^{\mathrm{a}}$ \\
SD & 0.3 & 0.3 & 1.3 & 3.1 & 0.2 & 0.2 \\
\hline
\end{tabular}

different letters indicate significant differences between methods, $\mathrm{P}<0.05$, SD - standard deviation, APT - alkanes pair technique

Table 3. Mean DMI, DMD and FO predicted by the APT (c31:c32:c33) for T2

\begin{tabular}{lrl}
\hline Item & Mean & SD \\
\hline APT predicted DMI, kg DM/d & 4.0 & 0.9 \\
APT predicted DMD, \% & 45.9 & 3.1 \\
APT predicted faecal output, $\mathrm{kg} \mathrm{DM} / \mathrm{d}$ & 1.7 & 0.5 \\
\hline
\end{tabular}

SD - standard deviation, APT - alkanes pair technique

\section{DISCUSSION}

The results of the present work are in line with those of Ordakowski et al. (2001) where the faecal recovery of alkanes increased as the length of the alkane chain increased. In the same line, Brosh et al. (2003) showed a positive relationship between faecal recovery and the length of alkane chain. The DMI and DMD measured in vivo and predicted by the APT (Table 2) showed no significant differences, suggesting that this technique can be used to measure DMI and DMD in donkeys. Dry matter intakes observed in $\mathrm{T} 2$ in donkeys under grazing conditions are within the range reported for these animals by Colunga et al. (2005). In the same way the DMD of the diet observed in T2 is similar to the values reported by Carretero et al. (2005) for a similar mixed forage diet fed to Mexican donkeys too. Unfortunately there is little information on DMI and DMD published on donkeys making difficult to further compare our results, however the APT has been widely used in horses with good 
results. For example, DMD from 44 to $48 \%$ were reported in horses fed with Alta fescue and Caucasian bluestem in Virginia (USA) by Crozier et al. (1997), which are similar to the DMD values observed in this work.

\section{CONCLUSIONS}

The alkanes pair technique can be used to predict dry matter intake and digestibility in grazing donkeys, with levels of accuracy and confidence similar to those observed in other herbivores species.

\section{REFERENCES}

Ali H.A., Mayes R.W., Lamb C.S., Hector B., Verma A.K., Ørskov E.R., 2004. The potential of longchain fatty acids as diet composition markers: development of methods for quantitative analysis and faecal recoveries of these compounds in sheep fed mixed diets. J. Agr. Sci. 142, 71-78

Brosh A., Henkin Z., Rothman S.J., Aharoni Y., Orlov A., Arieli A., 2003. Effects of faecal n-alkane recovery in estimates of diet composition. J. Agr. Sci. 140, 93-100

Carretero-Roque L., Colunga B., Smith D.G., González-Ronquillo M., Solis-Méndez A., CastelánOrtega O., 2005. Digestible energy requirements of Mexican donkeys fed oat straw and maize stover. Tro. Anim. Health Pro. 37, Suppl. 1, 123-142

Colunga G.B., Arriaga-Jordán C.M., Velásquez Beltran L., González-Ronquillo M., Smith D.G., Estrada-Flores J., Rayas-Amor A., Castelán-Ortega O.A., 2005. Participatory study on feeding strategies for working donkeys used by campesino farmers in the highlands of central Mexico. Tro. Anim. Health Pro. 37, Suppl. 1, 143-157

Crozier J.A., Allen V.G., Jack N.E., Fontenot J.P., Cochran M.A., 1997. Digestibility, apparent mineral absorption and voluntary intake by horses fed alfalfa, tall fescue and Caucasian bluestem. J. Anim. Sci. 75, 1651-1658

Dove H., Mayes R.W., 2003. Wild and domestic herbivore diet characterization. Satellite Meeting of VI International Symposium on the Nutrition of Herbivores. Mérida (México)

Gudmundsson O., Gudrun A., 1998. Evaluation of n-alkanes for intake and digestibility determination in horses. In: Techiques for Investigation Intake and Ingestive Behaviour by Farm Animal. IXth European Intake Workshop. IGER, Devon (UK)

Mayes R.W., Dove H., 2000. Measurement of dietary nutrient intake in free-ranging mammalian herbivores. Nutr. Res. Rev. 13, 107-138

Mayes R.W., Lamb C.S., Colgrove P.M., 1988. Digestion and metabolism of dosed even-chain and herbage odd-chain n-alkanes in sheep. In: A. Conway (Editor). Proceedings of the 12th General Meeting of the European Grassland Federation. Wicklow: Wicklow Press, pp. 159-163

Ordakowski A.L., Kronfeld D.S., Holland J.L., Hargreaves B.J., Gay L.S., Harris P.A., Dove H., Sklan D., 2001. Alkanes as internal markers to estimate digestibility of hay or hay plus concentrate diets in horses. J. Anim. Sci. 79, 1516-1522

Smith D.G., Mayes R.W., Hollands T., Cuddeford D., Yule H.H., Malo C.M., Gillen E., 2007. Validating the alkane pair technique to estimate dry matter intake in equids. J. Agr. Sci. 145, 273-281 